\title{
Assessing the Impact of Sustainable Development in NRCRI With Regards To Environmental Aspects: Health and Safety With Regards To the Engineering Departments and Field Farm Workers
}

\author{
M.N. Mbadiwe, C.C. Onyeka, C.C. Nwokoro And T.U. Madu \\ National Root Crops Research Institute Umudike, Abia State Nigeria.
}

\begin{abstract}
In recent times, there has been an increase in the rate of pollution of our environment and this is evident as shown in rapid climate change, ozone layer depletion, toxic pollution, depletion of non renewable resources, acidification and eutrofication of our soils and water. With all these environmental challenges, there is still increase in population and more mouths to feed. If these effects are not controlled or reduced, it means that before long, there will be an increase in the extinction of species, scarcity of fresh water and possibly more extreme weather conditions and loss of agricultural production and biodiversity,

As a foremost research institute, we have goals and mandates to meet with regards to roots and tuber crops and achieving these set goals and mandates will promote sustainable agricultural development in our country. On the other hand, these mandates can only be achieved by our human workforce if they work under a safe and protected environment. Therefore, it is very important that we make sure that our work does not in any way affect our employees or add to the jeopardy of the environment because it is the workforce that will see to it that our mandates are achieved under sustainable development.

In a country like Nigeria, it is naturally believed that Health, Safety and Environment is only synonymous with the oil and gas sector, big construction companies, engineering and manufacturing firms. As a research institute in the Agricultural sector, we carry out research work that involves our employees working in different laboratories where the work with different types of chemicals and organisms that are hazardous to health, we have field operations in the farms where our employees work with hand held tools and are exposed to different harsh weather conditions, engineering sector, wielding units as well as kitchen departments and other various units.
\end{abstract}

\section{Introduction}

Sustainability and Sustainable Development has become an important aspect of our current production and consumption policy. Many leaders in the various sectors including the agricultural sector have realized the importance of these issues and therefore have implemented their organization's vision and duty based on sustainability principles so as to sustain and protect their businesses from unforeseen risks. There has been growing concerns about the issue of sustainability and Agriculture.

Sustainable according to Encarta dictionary, means been able to maintain something over a period of time. According to The Brundtland's report of 1987, Sustainable development is defined as the development that meets the needs of the present without compromising the ability of the future generations to meet their own needs. (Strong \& Hemphill 2006). The three factors of sustainability or sustainable development lies in progress within three dimensions: economic development, environmental protection and social cohesion. (Jenkins and Yakovleva, 2006).

Health is the total good, physical, emotional and mental state of an individual and not a mere absence of diseases which the individual, the business and the nation need for sustainable development. (Fubara, 2002). Safety is the Protection of people from any form of accident, injury or harm or damage to equipment. (Fubara, 2002). Accident is defined as any unwanted or unplanned event that could lead to injury, ill health, death or damage to properties or equipment. (Fubara, 2002)

The agricultural sector is one that is expanding and has a major role to play in sustainability issues and therefore can be seen as one area that promotes the three pillars of sustainability. Agricultural Research Institutes play very important roles to see that sustainability in agriculture is achieved and National Root Crops Research Institute (NRCRI) Umudike is one of such institutes that are playing a major role in agriculture when it comes to root and tuber crops.

For the purpose of this paper, I want to look at how National Root Crops Research Institute is addressing the issue of sustainable development in agriculture with regards to the environmental aspects of health and safety in the engineering departments and the field farm workers. With the increasing concern of 
sustainability, the need for making sure that our institute is compliant with these factors of sustainability is very important especially as ISPON Act 2014 has been signed into law in the country.

\section{Materials And Methods}

The focal point of this research project is to critically evaluate the impact of Sustainable Development in NRCRI with regards to Health and Safety.

The main material used for this research work was the use of questionnaires presented to the Engineering department and field farm employees. For the preparation of the questionnaires, site visits were carried out to the various engineering departments and the farm fields to physically observe things, short oral interviews that involved questions and discussions between me and different employees from the various departments were all used to build the questionnaires that were later handed over to these employees which they all filled and returned.

\section{Results And Discussion}

This chapter will critically analyze the impact of Sustainable development with regards to health and safety. The critical analysis will be based on the answers and feedbacks gotten from the questionnaires that were distributed to the different employees in the selected departments.

\section{Results}

\section{Engineering Unit:}

The employees in this department have heard of health and safety and have undergone training in this area though not all of them. Most of their works involves use of fire and other forms of machinery. The institute provides them with Personal Protective wear but the PPE provided are the wrong types that are not meant for the kind of jobs been carried out and a lot more of the required PPE are not provided for them. Their machines are not guarded and some of them are faulty which pose as risk to them. Some of the units have fire extinguishers while others don't and they have not been trained on how to use the fire extinguishers. They have emergency fire exit points but have no fire alarm systems or muster points to gather in case of an emergency. There is no first aid kit and neither do they go for routine medical checkups.

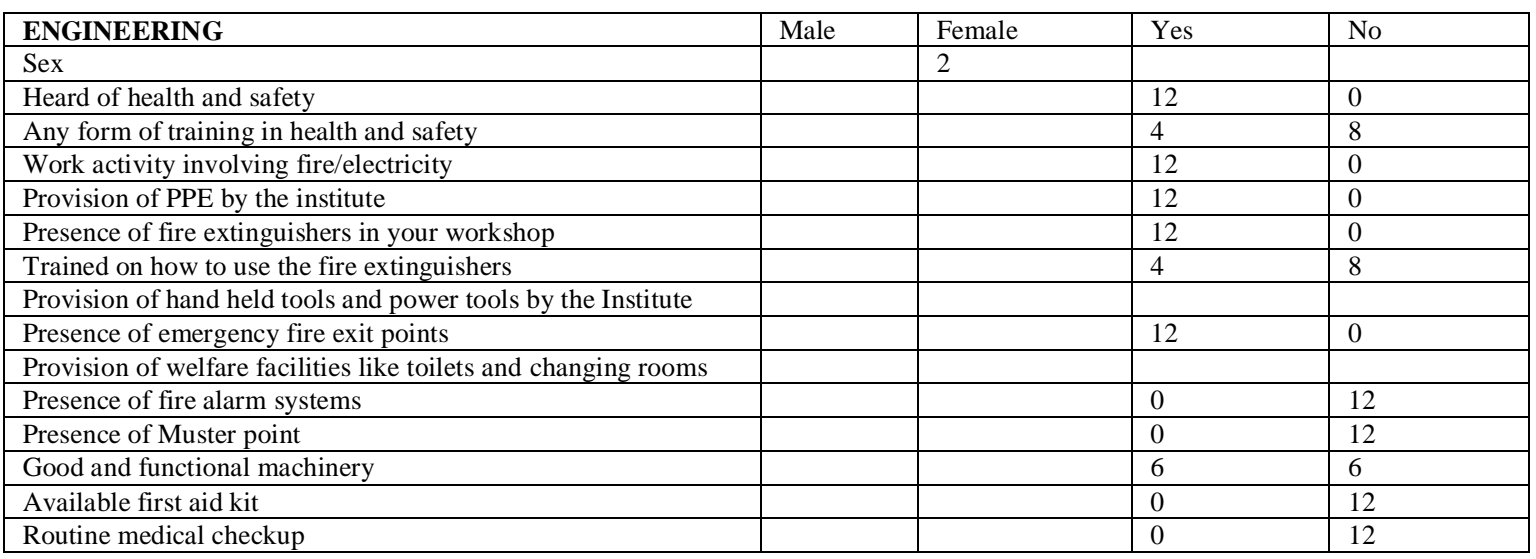

Table 1

\section{Farm field Staff:}

For the field farm staff, some have heard of health and safety while others have not but none of them have undergone any form of training on health and safety. Every field staff admitted that their farm fields were far from office areas and had to get these fields via trekking long distances. Their work involved manual labor ranging from planting, ridging, weeding, fertilizer application, spraying of chemicals and other field activities. The institute provides them with PPE though incomplete while some don't even get any PPE. There are no farm shades on this fields which can serve as muster points in case of emergency and also as shelter in case of rains. Some of these field farmers practice wrong farming methods and such example is during fertilizer application were the entire field farmers ticked yes on using their bare hands to apply this fertilizer to our crops. They field farmers involved in spraying of chemicals do not go for routine medical checkups and do not wear proper PPE. They field farmers do not enter the fields immediately to work after chemical spray has been carried out on the farms. 
Assessing the Impact of Sustainable Development in NRCRI With Regards To Environmental Aspects:

\begin{tabular}{|l|l|l|l|}
\hline FARM FIELD & Male & Female & Yes \\
\hline Sex & 14 & 16 & \\
\hline Heard of health and safety & & 11 \\
\hline Any form of Training in health and Safety & & 0 \\
\hline Distance to farm fields (btw far and near, all the officers ticked far) & & & 19 \\
\hline Does your work activity involve manual labor & & 30 \\
\hline Do you wear PPE while working & & 30 \\
\hline Provision of PPE by the institute & & 10 \\
\hline Are your farm fields sprayed with chemicals(herbicides, pesticides) & & 10 \\
\hline Provision of hand held tools by the Institute & & 30 \\
\hline Entry of farm fields immediately after chemical spray & & \\
\hline $\begin{array}{l}\text { Fertilizer application(almost all officers ticked the use their bare } \\
\text { hands for fertilizer application) }\end{array}$ & & 20 \\
\hline $\begin{array}{l}\text { New method of cutting cassava stems(most of the officers ticked no } \\
\text { to using this new method) }\end{array}$ & & 0 \\
\hline Presence of Farm shades & & 21 \\
\hline Routine medical checkup & & 0 \\
\hline
\end{tabular}

Table 2

\section{Conclusions}

Studying all the questionnaires gathered, I observed that though most of our employees especially in the engineering department have heard about health and safety unlike those working in the farm fields who have not heard about health and safety nor trained on it and therefore don't understand what it means for one to be safety conscious and work in a safe environment. With regards to the engineering department, I observed from my oral discussions with the employees, that it was more of the senior staff employees who have heard about health and safety because most of them belong to engineering associations where by they attend conferences and training which safety is part of but this could not be said for the junior employees. With regards to PPE, most of the employees in engineering department do not have PPE while some work with inappropriate PPE and such an example is where some of them wear lab coats instead of coveralls while working. Other PPEs like ear muffs, safety boots and gloves are not provided for the employees. Some don't even wear the provided PPE because they do not feel comfortable in them and some because they do not know the essence or advantages of wearing PPE because of lack of safety culture. I also observed that the field farm workers also have problems with PPE where most of them don't want to wear the provided PPE because is inappropriate and makes them uncomfortable. Another major concern was the perception a lot of the field farmers had with regards to safety issues.

My conclusions are that when it comes to promoting a sustainable environment where our research work can find solutions to our agricultural needs and that of the future generation, we are meeting our targets and mandate but then the safety of those who are working to achieve these mandate have to be looked into properly. Generally we lack positive safety culture in the system.

\section{Recommendations}

As a research institute, we have mandates and set targets to meet and all this can only be achieved with our human work force when they work in a conducive, safe and sustainable environment. The health and safety of our workers will not only promote sustainability but will also save the institute money when it comes to sick live and loss of work hours.

From the interviews, I learnt that most of the PPE are supplied by contractors so I recommend that these contractors should meet with the various heads of these different departments so as to brief them on what type and quality of PPE that they need that will suit their job specification. Every job is peculiar and therefore need their own peculiar PPE. What suits an employee working in the engineering department cannot suit an employee working out in the field. The Institute has to show commitment to health and safety starting from the management down to the employees by putting in place and implementing a health and safety policy. I also recommend that the institute should start looking towards training our employees on health and safety and were if possible work towards having a health and safety unit that will help correct and change our perception/attitudes towards a safe working environment that is sustainable and promotesa positive safety culture. This is very important especially as the Federal Government has signed the ISPON Act 2014 into law which every organization has to be compliant to be it private or public sector. 


\section{References}

[1]. Appleton, F.A. (2006) ‘Sustainability: A practitioner’s reflection’ Technology in Society, 28(1-2) 3-18

[2]. Encarta Dictionary; English North America (2012)

[3]. Fubara, B. A. (2002) Safety Management

[4]. General HSE Training Manual - Institute of Safety Professionals of Nigeria

[5]. HSE- Farmwise, Your Essential Guide to Health and Safety in Agriculture.

[6]. Hughes, P. and Ferrett Ed, (2008) Introduction to Health and Safety at Work, Third Edition: The Handbook for the NEBOSH National General Certificate.

[7]. Jenkins, H. and Yakovleva, N., (2006) Corporate social responsibility in the mining industry: Exploring trends in social and environmental disclosure. Journal of Cleaner Production, 14(3-4), 271-284.

[8]. URL 1: http://www.hse.gov.uk/agriculture/topics/welfare.htm (Assessed October 24th 2014)

[9]. Wentz, C. A., (2000) Safety Health and Environmental Protection. 